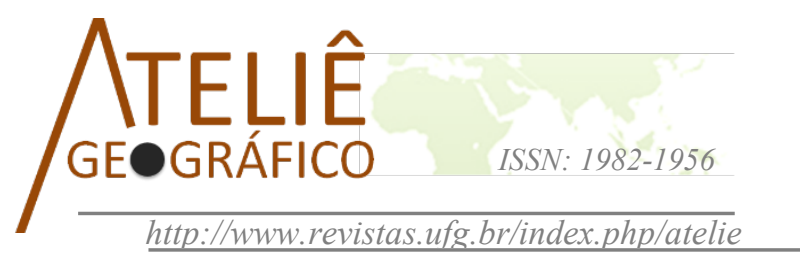

\title{
Uso corporativo do território e a nova divisão territorial do trabalho da indústria do vestuário no Rio Grande do Norte
}

\author{
Corporate usage of the territory and the new Territorial \\ division of labor in Rio Grande do Norte's garment industry.
Uso corporativo del territorio y la nueva división territorial del trabajo de la industria de vestuario en Rio Grande do \\ Norte
}

Leonardo da Silva Galindo

Universidade Federal do Rio Grande do Norte

leonardogalindo.ufrn@gmail.com

Francisco Fransualdo de Azevedo

Universidade Federal do Rio Grande do Norte

ffazevedo@gmail.com

\begin{abstract}
Resumo
A produção do vestuário no Rio Grande do Norte (RN) caracterizava-se pela concentração de empresas e empregos em Natal. Recentemente houve redução dessas variáveis na capital, enquanto observou-se movimento contrário no interior do estado. O objetivo deste artigo é compreender as transformações na divisão territorial do trabalho da indústria do vestuário no RN. A metodologia contemplou revisão bibliográfica, sistematização de dados secundários e pesquisa empírica. Constatamos uma redefinição da divisão do trabalho, com agentes promovendo um uso corporativo do território. Este provoca a dispersão de unidades produtivas que realizam serviços de costura para municípios do Seridó potiguar. Já as grandes fábricas continuam no comando da produção realizando outras etapas do processo produtivo em Natal e Parnamirim. A terceirização da costura consolidou no Seridó uma divisão interna do trabalho voltada ao setor têxtil e de confecções, com alguns municípios realizando a costura para grandes indústrias, e outros se especializando em produzir acessórios do vestuário e artefatos têxteis para uso doméstico.
\end{abstract}

Palavras-chave: Rio Grande do Norte; vestuário; divisão territorial do trabalho; terceirização. 


\begin{abstract}
The garment production in Rio Grande do Norte (RN) used to be characterized by a concentration of companies and job opportunities in Natal. Recently, there was a reduction of these variables in the aforementioned capital, while a contrary movement was observed in the countryside of the state. The aim of this paper is to understand the changes in the territorial division of labor of the garment industry in RN. Methodology included bibliographic review, systematization of secondary data and empirical research. We found a redefinition of the division of labor, with agents promoting corporate usage of the territory. This causes dispersion of the production units that perform sewing services to municipalities in the Serido region of the state. In contrast, the large factories continue to be in charge of production by performing other stages of the production process in the cities of Natal and Parnamirim. The outsourcing of the sewing production consolidated in Seridó an internal division of labor focused on the textile and clothing sector, with some municipalities sewing for large factories, while others specializing in producing clothing accessories and household textile articles.
\end{abstract}

Keywords: Rio Grande do Norte; garment; territorial division of labor; outsourcing.

\begin{abstract}
Resumen
La producción de vestimenta en Rio Grande do Norte (estado de Brasil) se caracterizaba por la concentración de empresas y empleos en Natal. Recientemente ha habido reducción de esas variables en la capital, mientras que había movimiento opuesto en el interior del estado. El objetivo de este artículo es comprender las transformaciones en la división territorial del trabajo de industria del vestuario en el RN. La metodología incluyó revisión bibliográfica, sistematización de datos secundarios y la investigación empírica. Observamos una redefinición de la división del trabajo: varios agentes promovieron un uso corporativo del territorio llevando la dispersión de unidades productivas que realizan servicios de costura para municipios del Seridó potiguar. Las grandes fábricas continúan al mando de la producción realizando otras etapas del proceso productivo en Natal y Parnamirim. La tercerización de la costura consolidó en el Seridó una división interna del trabajo dirigida al sector textil y de confecciones, con algunos municipios realizando la costura para gran industrias, y otros especializándose en producir accesorios de la vestimenta y artefactos textiles para uso doméstico.
\end{abstract}

Palabras clave: Rio Grande do Norte; vestimenta; división territorial del trabajo; externalización.

\title{
Introdução
}

No processo de formação socioespacial brasileiro a indústria e seus vetores de produção estabeleceram-se principalmente na Região Concentrada (SANTOS, SILVEIRA, 2004), com particularidades regionais de acordo com os interesses e lógicas espaciais das empresas. Na Região Nordeste houve uma especialização produtiva em setores que se caracterizam pelo emprego de mão de obra barata (REONLON, 2013), porém praticamente restritas as regiões metropolitanas das capitais estaduais (como Fortaleza, Recife e Natal).

No Rio Grande do Norte (RN) a produção do vestuário destacou-se e historicamente apresentou maior concentração espacial em Natal e Parnamirim (AZEVEDO, GALINDO, 2016; FIERN, 2016). Porém, desde os anos 2000 verificou-se transformações na divisão territorial do trabalho das indústrias de confecções no $\mathrm{RN}$, com diminuição de 
estabelecimentos e empregos na capital e crescimento dessas variáveis no interior, em especial na região do Seridó Potiguar ${ }^{1}$.

Nesse contexto, o objetivo deste artigo é compreender as transformações na divisão territorial do trabalho da indústria de confecções de artigos do vestuário no RN. Para tanto, identificamos os agentes envolvidos na criação de uma nova configuração territorial para o estabelecimento da referida atividade: O Estado (Bancos públicos; poder municipal; Secretaria de desenvolvimento econômico do RN - SEDEC, poder legislativo) Sistema S SEBRAE e SENAI; grandes grupos industriais e microempresários.

A pesquisa teórica baseou-se nos conceitos de território e lugar. O primeiro é entendido a partir da categoria território usado. Segundo Santos (2005, p. 255) "é o uso do território [...] que faz dele objeto da análise social [...]. O território são formas, mas o território usado são os objetos e as ações, sinônimo de espaço humano, espaço habitado". O território é usado por todos: pessoas, instituições, empresas, etc., levando a criação de variadas formas de uso. Mas alguns agentes tem maior capacidade de produzir a configuração territorial que melhor atenda a seus interesses

No capitalismo, o Estado e as multinacionais são os agentes com maior capacidade de ação (SANTOS, 2012) praticam um uso corporativo do território, que segundo Kahil (2010, p. 478) é a "forma hegemônica de compartilhar o espaço no capitalismo contemporâneo".

O uso corporativo do território caracteriza-se pela hegemonia na produção de normas e objetos que atendem a racionalidade do Estado e das grandes empresas e "tem a força de determinar a tendência de todas as demais formas de desenvolvimento do processo de produção material da vida na fase atual do capitalismo" (KAHIL, 2010, p. 478).

Por sua vez, a produção de um sistema de normas e objetos depende da formação de uma solidariedade organizacional, que "supõe uma interdependência até certo ponto mecânica, produto de normas presididas por interesses de modo geral mercantis, mutáveis em função de fatores do mercado." (SANTOS, 2001, p. 48).

Para Santos e Silveira (2004, p. 290) “cada atividade [...] produz sua própria divisão do trabalho". Nesse contexto entra em questão o papel do lugar. Cada lugar tem singularidades que o tornam propício a abrigar determinadas atividades em detrimento de outras. Para Santos

Os lugares se distinguiriam pela diferente capacidade de oferecer rentabilidade aos investimentos. Essa rentabilidade é maior ou menor, em virtude das condições locais de ordem técnica [...] e organizacional [...]. Podemos, também, falar de produtividade espacial ou produtividade geográfica, noção que se aplica a um lugar, mas em função de uma determinada atividade ou conjunto de atividades. [...]. Tal produtividade pode não ser duradoura, desde que outro lugar passe

\footnotetext{
${ }^{1}$ A região Seridó potiguar é formada por 24 municípios, localizados no centro-sul do RN. Mais informações sobre a formação territorial da região, consultar Morais (2004).
} 
a oferecer àquele produto melhores vantagens comparativas de localização. (SANTOS, 2012, p. 247-248).

Destarte, será discutido como o uso corporativo do território constituído a partir da solidariedade organizacional dos agentes citados, criou condições para transformações na divisão do trabalho da indústria do vestuário que propiciaram o desenvolvimento da referida atividade em determinados lugares do $\mathrm{RN}$.

Dentre os dados secundários utilizamos: IBGE, com o banco de dados "pesquisa industrial anual" e "censo industrial de 1970"; a plataforma RAIS do Ministério do Trabalho e Emprego que apresenta a evolução do número de estabelecimentos e da população ocupada na produção do vestuário por município; e a Federação das indústrias do estado do Rio Grande do Norte (FIERN) com o banco de dados "Guia Industrial que apresenta o endereço das empresas que atuam no setor, número de funcionários e telefone".

A pesquisa de campo consistiu em observação simples, sistematizada e entrevistas semiestruturadas com representantes da SEDEC; do SEBRAE; proprietários das facções de costura e trabalhadores. Ocorreu entre 6 de julho e 18 de outubro de 2017, em 15 municípios: Natal, Parnamirim, São José de Mipibu, Vera Cruz, Ceará-Mirim, Santa Cruz, Acari, Parelhas, Jardim do Seridó, São José do Seridó, Cruzeta, Jucurutu, São Francisco do Oeste, São Vicente e Lajes Pintadas.

O documento Guia Industrial FIERN apontava para a existência de 149 facções de costura no estado. As entrevistas abarcaram dados de 66. Outras 28 encerraram suas atividades e 5 não eram facções de costura. As demais não foram visitadas ou não forneceram dados para a pesquisa.

\section{A divisão territorial do trabalho industrial no Brasil}

Conforme Santos e Silveira (2004) há tantas divisões territoriais do trabalho possíveis conforme a quantidade de atividades desenvolvidas. O que dizer do setor industrial? Apenas a seção de "indústrias de transformação" contempla empresas de diversos segmentos como alimentos, bebidas, têxteis, vestuário e acessórios, derivados do petróleo, farmacêuticos, máquinas e aparelhos elétricos, veículos automotores, etc. ${ }^{2}$. Cada um engloba empresas de variados tamanhos e circuitos espaciais produtivos com escalas local, regional, nacional e global.

A figura 01 é uma simplificação da divisão territorial do trabalho industrial do Brasil. Contempla a distribuição espacial de unidades produtivas e trabalhadores formais. Por apresentar uma visão generalista, essa representação condensa grande diversidade de tipologias de indústrias e topologias de empresas. Nota-se o uso industrial do território é mais denso em alguns lugares e rarefeito em outros.

\footnotetext{
${ }^{2}$ Para mais informações, IBGE, 2007.
} 


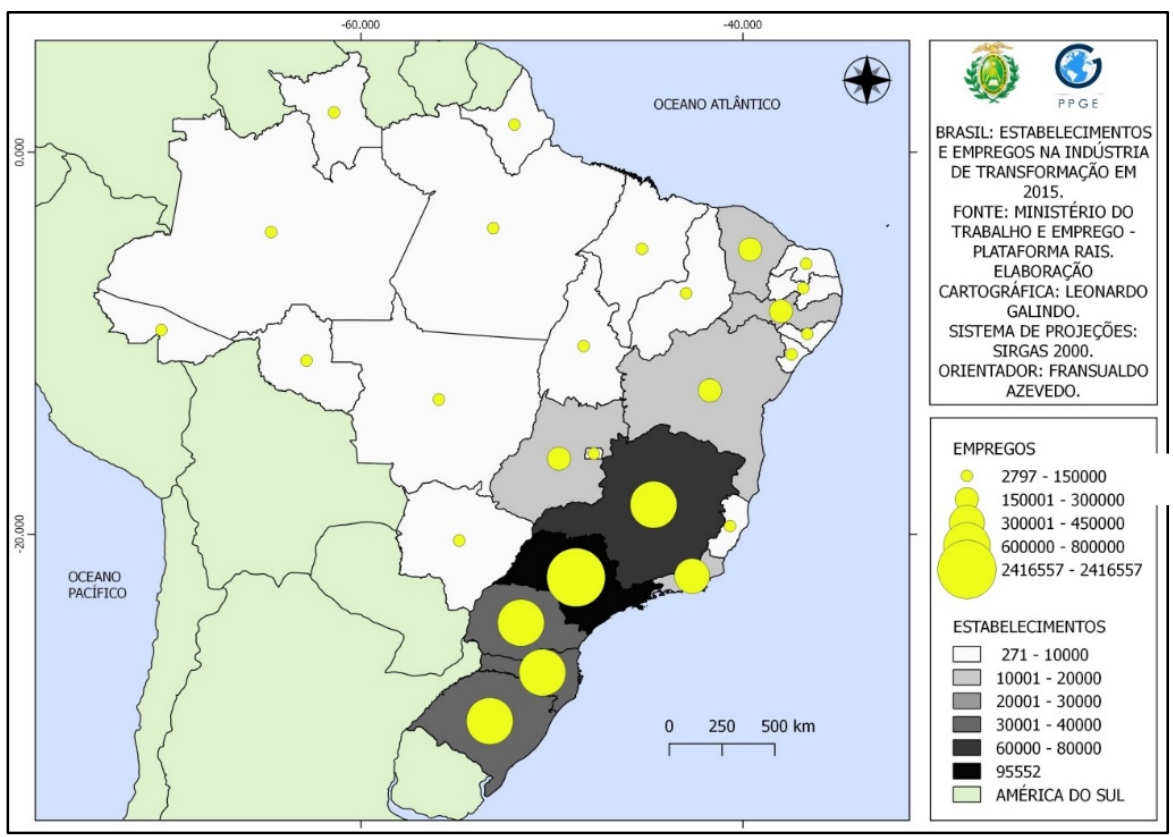

Figura 01: Brasil: Número de estabelecimentos e empregos na Indústria de transformação em 2015.

Fonte: GALINDO, 2018.

Apenas cinco unidades federativas (SP, MG, RS, SC e PR) abrigavam 68,65\% das indústrias em 2015 e 69,97\% dos empregos (RAIS, 2016). Em São Paulo estavam instaladas $26,60 \%$ das indústrias e $33,08 \%$ dos trabalhadores. O que explica a atual divisão territorial do trabalho industrial do Brasil?

A divisão territorial do trabalho industrial decorre do processo de formação socioespacial, em que os lugares que compõem o atual território brasileiro assumiram diferentes funções. Em São Paulo a ocupação do território ocorreu principalmente a partir da monocultura do café (CANO, 1998a). A isso se alia a constituição de um mercado consumidor originado pela presença de mão de obra de imigrantes assalariados de origem europeia durante o final do século XIX e início do século XX.

Consequentemente houve maior aprofundamento das relações capitalistas de produção em SP se comparado ao Nordeste, as quais contribuíram para um processo de industrialização no início do século XX. Este se intensifica a partir de eventos como a Grande Depressão; as ações do governo Vargas; a Segunda Guerra Mundial; pelos investimentos de empresas multinacionais (CANO, 1998a; FURTADO, 2007).

O processo de industrialização estará consolidado em São Paulo e outros estados do Centro-Sul quando a ação da SUDENE começa a promover o uso industrial do território no Nordeste. Neste, a ocupação deu-se a partir da economia canavieira no litoral oriental, 
criação de gado e cotonicultura no semiárido (ANDRADE, 1995). Foram essas as principais atividades desenvolvidas até meados da década de 1960.

Nesse contexto, a formação da Região Concentrada (SANTOS; SILVEIRA, 2004) teve como principal motor a atividade industrial, que estimulou a integração do território nacional por meio da construção de rodovias e outras infraestruturas (FURTADO, 2007; REOLON, 2013; PEREIRA JUNIOR, 2011).

Embora a Região Concentrada seja atualmente definida a partir do papel de comando exercido pelo setor financeiro, de comércio e serviços, não é à toa que a mesma abriga mais de dois terços dos estabelecimentos industriais do Brasil. Nesse sentido, "o trabalho já feito se impõe sobre o trabalho a fazer. A atual repartição territorial do trabalho repousa sobre as divisões territoriais do trabalho anteriores." (SANTOS, 2012, p. 141).

Isso reflete até hoje as diferenças de densidade industrial. Em 2015 os estados nordestinos abrigavam 13,71\% das indústrias de transformação e 13,61\% dos empregos formais. Mas Bahia, Ceará e Pernambuco somavam 67,62\% das unidades produtivas da região e $67,02 \%$ da mão de obra ocupada (RAIS, 2016).

Chegamos ao segundo fator explicativo para a atual divisão do trabalho industrial: embora apresente maior densidade na Região Concentrada, uma parte das fábricas distribuise, sobretudo a partir de manchas e pontos nos três estados nordestinos citados anteriormente.

Esse fato decorre da existência de ações que promoveram a desconcentração espacial das unidades produtivas: a SUDENE a partir dos anos 1960 (MOREIRA, 1979), e a "Guerra dos Lugares" na década de 1990 (SANTOS; SILVEIRA, 2004). Elas impulsionaram o uso industrial do território por meio da ação coordenada entre Estado e empresas como a renúncia de impostos e criação das infraestruturas: rodovias, portos e doação de terrenos (PEREIRA JÚNIOR, 2011).

Essas ações provocaram uma “desconcentração concentrada” (REOLON, 2013), com transferência de unidades produtivas para o interior do estado de São Paulo e para os três estados nordestinos citados - especialmente para as regiões metropolitanas de suas respectivas capitais. Enquanto o controle da produção permaneceu centralizado graças a avanços das tecnologias de informação e comunicação. (REOLON, 2013; PEREIRA JÚNIOR, 2011, SILVA, 2013).

O deslocamento espacial da indústria deu-se em direção aos estados nordestinos, devido a menor organização da força de trabalho local e menores salários (REOLON, 2013; PEREIRA JÚNIOR, 2011) em relação ao observado na Região Concentrada. Nesse contexto, qual o papel desempenhado pelo Rio Grande do Norte no que concerne a produção industrial? Quais as características da indústria de transformação presente no estado? 


\section{A indústria de transformação do Rio Grande do Norte: especialização produtiva em artigos do vestuário.}

O Rio Grande do Norte apresenta pouca expressividade no que concerne à Divisão Territorial do Trabalho Industrial no Brasil, tanto em relação ao número de estabelecimentos quanto ao de empregos. $\mathrm{O}$ estado contava com 1,02\% das unidades industriais do país e apenas $0,83 \%$ dos vínculos formais (RAIS, 2016). Apesar da pouca representatividade, o $\mathrm{RN}$ participa da divisão do trabalho industrial por abrigar empresas do setor têxtil e confecções, cuja produção/comercialização abrangem todo o território nacional.

As indústrias de confecções eram as maiores empregadoras industriais do $\mathrm{RN}$ em 2015. Dos 60.461 trabalhadores do setor secundário, mais de $1 / 4$ deles ocupavam-se na fabricação de artigos do vestuário ${ }^{3}$ (RAIS, 2016). Em números totais eram 16.220 trabalhadores, representando $15,38 \%$ da região Nordeste, e $2,84 \%$ do país. (RAIS, 2016).

Quanto ao valor da produção (figura 02), respondia por $15,79 \%$ do total gerado no Nordeste (atrás apenas do Ceará) e por $2,32 \%$ do total nacional (IBGE, 2016).

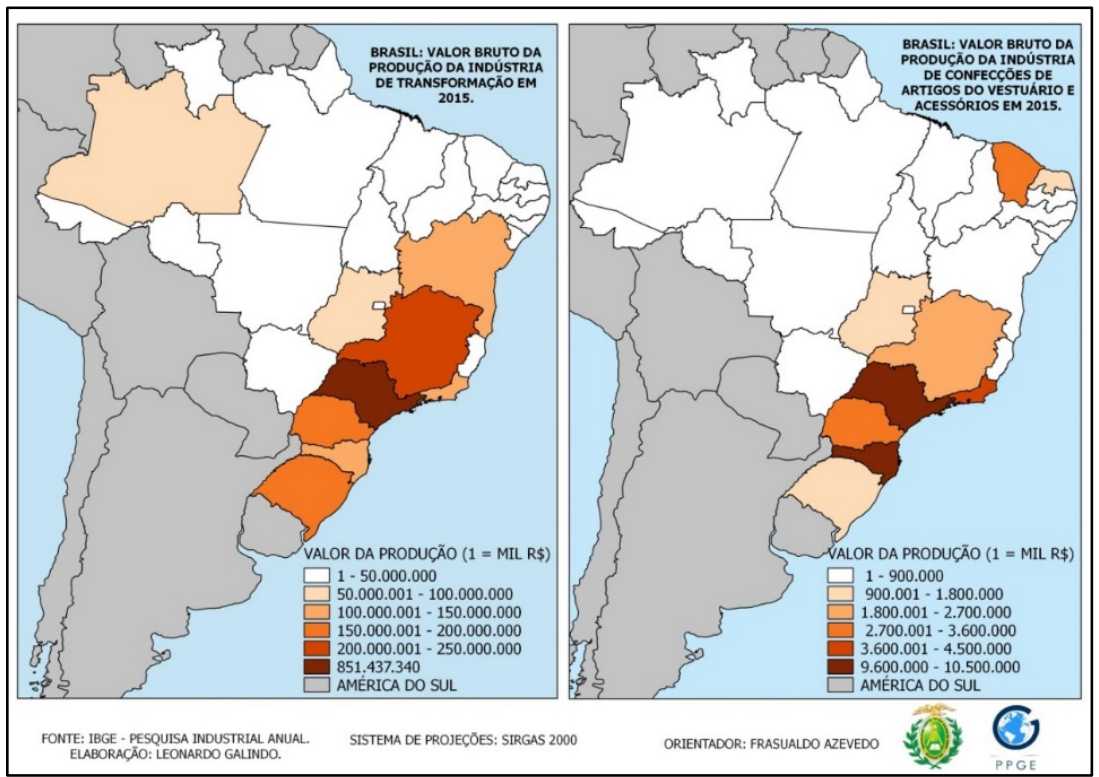

Figura 02 (a e b): Brasil: Valor bruto da produção da indústria de transformação (a) e da indústria de confecções (b) por estado da federação em 2015.

Fonte: IBGE, 2016; Elaboração: Galindo, 2018.

\footnotetext{
${ }^{3}$ Para o IBGE (2007) a fabricação de artigos do vestuário envolve a produção de "vestuário masculino, feminino e infantil (camisas, camisetas, blusas, vestidos, saias, calças, ternos, casacos”, etc.).
} 
Embora com menor expressividade que os estados do Ceará, Bahia e Pernambuco, o Rio Grande do Norte participou do processo de restruturação industrial pelo qual passou o Brasil, atraindo alguns segmentos produtivos, destacando-se na fabricação do vestuário.

Para isso foi importante à ação do Estado, que criou condições propícias (normativas e de infraestruturas) para a alocação e atuação das empresas. Destacamos a SUDENE; as políticas de planejamento nos anos 1970 (BARBOSA, 2015); os programas de atração de indústrias, como o PROADI e o Pró-Gás nos anos 1980 e 1990, respectivamente; e a criação de distritos industriais. Tais ações resultaram na construção seletiva de infraestruturas, priorizando algumas porções do território potiguar4.

A política do Estado relacionada à política das empresas convergiu para o uso industrial do território no $\mathrm{RN}$ principalmente na região metropolitana de Natal, a qual conta com dois distritos industriais: O Centro Industrial Avançado, e o Distrito Industrial de Natal (ARAÚJO, 2009).

A ação do Estado, embora objetivasse atrair vários ramos industriais acabou beneficiando a produção do vestuário no Rio Grande do Norte. Em 2010, 50,93\% dos estabelecimentos do setor localizavam-se em Natal e Parnamirim (RAIS, 2016).

Apesar disso, notamos uma mudança em curso, que tem início nos anos 2000 e se intensifica a partir de 2010 - a dispersão dessa atividade para o interior, sobretudo na microrregião do Seridó Oriental (figura 03).

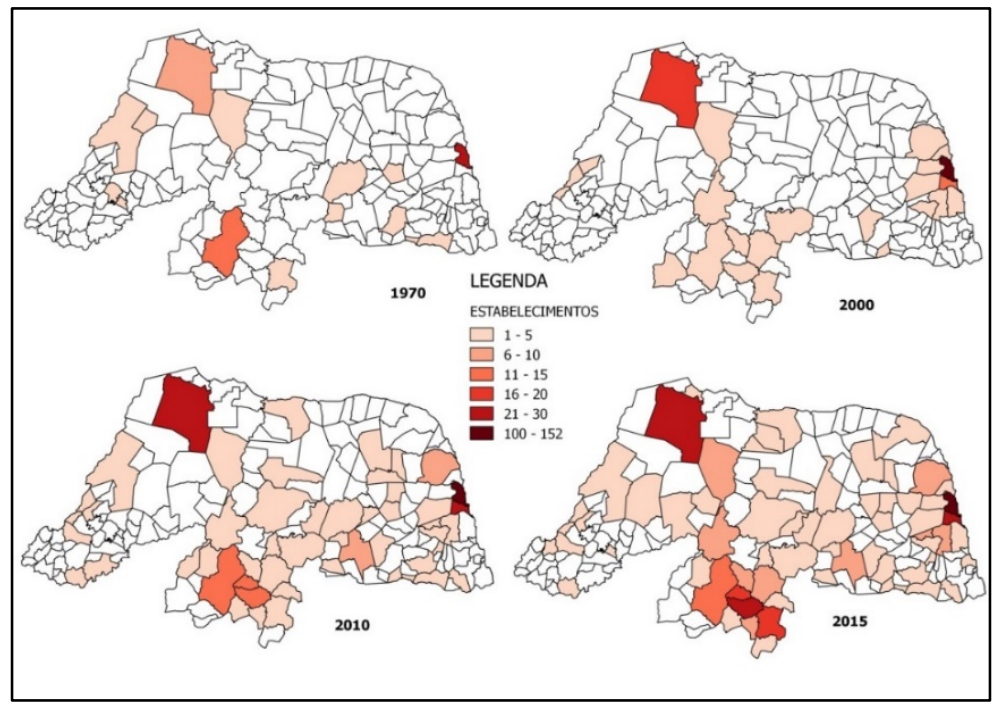

Figura 03: Rio Grande do Norte: Evolução do número de estabelecimentos da indústria de confecções entre 1970 e 2015.

Fonte: IBGE, 1970; RAIS, 2016. Elaborado e adaptado por GALINDO, 2018.

${ }^{4}$ Para mais informações sobre os programas PROADI, Pró-Gás e os distritos industriais, consultar: Barbosa, 2015; Tavares, 2017; Araújo, 2006; Galindo, 2018. 
Os dados do Censo industrial de 1970 e da plataforma RAIS mostram que apesar de Natal continuar com maior concentração de estabelecimentos, mais da metade dos municípios passam a registrar essa atividade, com expressivo crescimento em Mossoró e na região do Seridó. As informações da FIERN (2016) evidenciaram que mais da metade das unidades produtivas de Mossoró são pequenas empresas de confecções de fardamentos, enquanto que no Seridó tem-se à disseminação de pequenas unidades produtivas chamadas de facções de costura.

\section{As facções de costura e a nova divisão territorial do trabalho da indústria de confecções no Rio Grande do Norte}

O termo "facção" está relacionado à etapa da produção do vestuário que envolve os "serviços industriais de facção de blusas, camisas, vestidos, saias, calças, ternos e outras peças do vestuário (corte e costura de golas, punhos ou outras partes das roupas)" (IBGE, 2016).

O SEBRAE (S.D) apresenta uma definição mais precisa:

Facção é o nome dado às confecções que prestam serviços para outras empresas do ramo que possuem marca própria e foco na comercialização, dentro da cadeia produtiva do setor têxtil. Em geral uma facção não vende seus produtos diretamente no varejo, realizando somente trabalhos de corte, montagem e acabamento de peças do vestuário para outras confecções. (SEBRAE, p. 2, s.d).

A facção é o estabelecimento industrial (figura 04 e 5) que realiza uma ou mais etapas da produção de confecções (corte e costura, por exemplo) para uma indústria ou empresa varejista. Seus proprietários não têm o comando sobre o tipo de roupa ou a quantidade de peças produzidas.

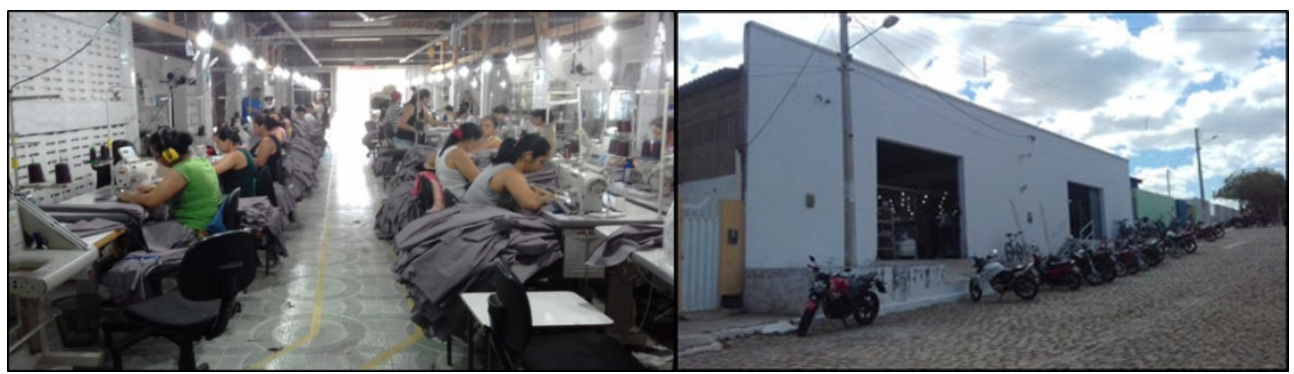

Figura 04: Funcionários trabalhando em facção de costura no município de Parelhas.

Fonte: Galindo, 2017.
Figura 05: Fachada de facção de costura em Acari, RN.

Fonte: Galindo, 2017.

São registradas facções de costura no RN desde o final da década de 1990 em Natal, Ceará-Mirim, Jardim do Seridó e São José do Seridó. Elas prestavam serviços de costura 
principalmente para a empresa RMNor do Brasil ${ }^{5}$, a qual tinha como principais clientes a C\&A, Renner e Zara (TAVARES, 2017; ARROYO, GOMES, 2013). Nos anos 2000 se instalou em Parnamirim uma fábrica da empresa Cia Hering, que segundo Tavares (2017) buscou aproveitar a rede de facções existentes no estado, tendo em vista que a empresa já utilizava esse serviço em Santa Catarina (LUCLKTENBERG, 2004). surgimento das facções no Nordeste se efetivou no contexto da reestruturação produtiva das indústrias do vestuário, que reorganizaram seu processo produtivo e terceirizaram algumas etapas, como a da costura, conforme estudado por Silva (2013):

A dispersão da produção, especialmente da subetapa da costura do circuito espacial de produção do vestuário, ocorreu principalmente em virtude dos altos preços da mão de obra nas áreas de produção mais antigas como São Paulo, dos incentivos fiscais, tributários e territoriais oferecidos às empresas para se deslocarem para o Nordeste. $\mathrm{O}$ aumento da facilidade proporcionada pela maior densidade de transportes e comunicações também contribui com fatores fundamentais para o deslocamento da produção para outras regiões do território brasileiro e mesmo do estado de São Paulo (SILVA, 2013 p. 5).

Apesar desse arranjo, a maior parte dos empregos e estabelecimentos relacionados à produção de confecções ainda localizava-se em Natal no ano de 2010. Em relação à quantidade de empregos, a concentração espacial devia-se principalmente a fábrica da Guararapes (hoje grupo Riachuelo), que agregava mais da metade dos trabalhadores (GALINDO, 2018). Esse grupo industrial controla todas as etapas do processo de produção do vestuário, que segundo Silva:

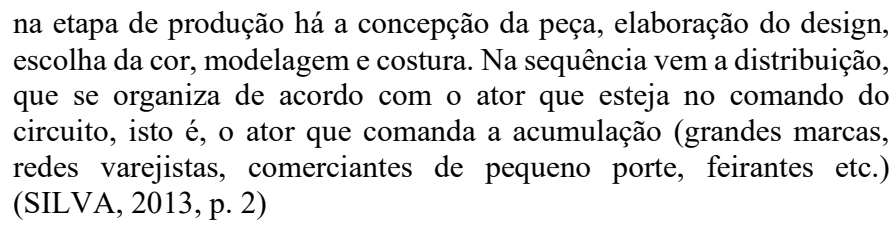

A unidade fabril da empresa em Natal era responsável pelas etapas: produção de tecido (para algumas peças do vestuário); lavagem; corte e costura. A partir de 2013 a referida fábrica passou a terceirizar parte da etapa da costura, contribuindo para uma nova configuração espacial da indústria de confecções no estado, com o estímulo a criação das facções de costura.

Essa mudança foi possível graças à construção de uma solidariedade organizacional envolvendo vários agentes, viabilizando o uso corporativo do território pelo ramo de confecções no Rio Grande do Norte. Para tanto, foi criado o programa Pró-Sertão ${ }^{6}$ em 2013 pela SEDEC. Em 2015, o programa passou a ser gerenciado pelo SEBRAE/Natal.

\footnotetext{
${ }^{5}$ Em pesquisa de campo detectamos que a empresa encerrou suas atividades no RN.

${ }^{6}$ Para mais informações consultar Galindo (2018) e SEBRAE (2013).
} 
Em pesquisa de campo, entrevistamos o então secretário adjunto da $\mathrm{SEDEC}^{7}$, que nos apresentou informações sobre a operacionalização do Pró-Sertão:

É fundamental destacar que o Pró-Sertão foi uma ideia do Governo, iniciada $100 \%$ na SEDEC. Somente após a consolidação com empresas do setor expandiu-se para demais parceiros, como pensado desde sempre, mas somente "divulgado" quando certeza do interesse das empresas nos moldes do promovido-idealizado. [...]. Fundamental também foi à articulação SEDEC com SEBRAE e sistema $\mathrm{S}$ para estruturar o projeto e sua execução com iniciativa privada.

O secretário adjunto destaca que o papel da SEDEC foi o de articulador entre os diversos agentes interessados no sentido de "gerar e iniciar o programa". Dentre ele: as grandes indústrias de confecções que comandam o processo de terceirização (Guararapes e Hering, com fábricas em Natal e Parnamirim respectivamente); o Estado (poder municipal, governo estadual por meio da Secretaria de Desenvolvimento Econômico, bancos públicos); o sistema S (SEBRAE e SENAI) e os proprietários das facções de costura.

Para viabilizar o uso corporativo do território pela indústria de confecções a atuação do Estado se deu por diversas formas, destacando-se o financiamento da compra das máquinas de costura. Os empresários de $53 \%$ das empresas visitadas na pesquisa empírica obtiveram todas as suas máquinas de costura a partir de crédito oferecido pelo Banco do Nordeste e outros $9 \%$ adquiriram parte do maquinário graças ao crédito disponibilizado pelo referido banco (GALINDO, 2018).

Quanto ao poder municipal, em 9 dos 15 municípios visitados, foi registrada pelo menos uma das seguintes ações em benefício do setor: doação de terreno para a construção de galpão de costura; concessão de prédios públicos para o funcionamento da facção; cobrança de valor simbólico pelo aluguel do prédio; formação de parcerias com o SENAI e o PRONATEC ${ }^{8}$ para a capacitação profissional; e subsídios dos valores de água e/ou energia elétrica para a facção (GALINDO, 2018).

O SEBRAE operacionaliza o Pró-Sertão orientando proprietários de facções em diversos aspectos: contratação, capacitação e organização da mão de obra; organização do contato entre o empresário e a indústria; assessoria - adequação as leis trabalhistas, como conseguir crédito, etc. A capacitação profissional fica a cargo do SENAI por meio dos cursos de costura industrial e mecânico de máquinas de costura.

Ao investirem na terceirização, as grandes indústrias diminuem os custos com a compra e manutenção de máquinas, bem como com os encargos trabalhistas. A fábrica da Guararapes em Natal, por exemplo, chegou a ter aproximadamente 12 mil funcionários em

\footnotetext{
${ }^{7}$ Entrevista concedida em 06/07/2017.

${ }^{8}$ Programa Federal de capacitação profissional criado em 2011 e atualmente desativado. Para o setor de confecções oferecia os cursos de mecânico de máquina de costura e costura industrial.
} 
2012 (FIERN, 2014), e se responsabilizava por partes dos custos com o transporte e alimentação/almoço desses funcionários ${ }^{9}$.

Todos esses custos foram eliminados com a terceirização da etapa de costura. A maioria das facções está em municípios pequenos, com população de 2 a 15 mil habitantes (IBGE, 2018) e distribuídos em áreas urbanas. Com isso, o empregado pode deslocar-se em poucos minutos caminhando, de bicicleta ou moto, e utilizar o horário de almoço para fazer as refeições em sua própria residência.

Todos os agentes envolvidos em viabilizar a produção do vestuário beneficiam-se pelos seguintes aspectos: As grandes indústrias conseguem reduzir seus custos e aumentar suas margens de lucro; os pequenos municípios passam a gerar empregos onde normalmente não havia opções de emprego formal e arrecadar mais ISS. Apesar dos baixos salários, (1 salário mínimo) há uma dinamização da economia local com efeitos nos circuitos superior e inferior da economia, especialmente a partir do aumento da circulação de dinheiro nas feiras livres; cria-se uma pequena classe média nas pequenas cidades formada pelos donos das facções de costura.

Os bancos públicos como o Banco do Nordeste juntamente com o SEBRAE e SENAI acabam por fomentar o aumento das relações capitalistas de produção no interior do estado e o primeiro aumentar seus lucros. Para os trabalhadores dos municípios há uma diminuição da dependência das políticas públicas de transferência de renda e as aposentadorias dos idosos, bem como diminui a propensão a migrar.

E qual o resultado de todas essas ações? No final de 2016 havia 149 facções de costura no RN, 64,4\% delas na mesorregião Central, em especial no Seridó Oriental; 21,48\% na mesorregião Leste potiguar, 8,72\% no Agreste e 5,6\% na mesorregião Oeste potiguar (figura 06). Quando consideramos a quantidade de vínculos formais de trabalho, 67,56\% estavam na mesorregião Central e apenas $14,1 \%$ no Leste potiguar. Trabalhavam nas facções 3.696 pessoas em 2016 (FIERN, 2016).

O que explica a maior concentração de estabelecimentos no Seridó? Por que essas facções não se estabeleceram na RMN, que tem uma maior proximidade com as fábricas contratantes ou em outros lugares, como oeste e norte do RN?

Recorremos à categoria analítica formação territorial e ao conceito de lugar. A primeira "dá aos lugares especificidades, criando diferenciações espaciais e dotando os lugares de aptidões que permitem a instalação, ou não, de determinadas atividades" (DANTAS, 2016, p.197). O segundo é compreendido como uma "funcionalização do mundo" em que se realiza um conjunto limitado de "possibilidades" (SANTOS, 1996, p. 13-14).

\footnotetext{
${ }^{9}$ A fábrica da empresa continua funcionando com menor número de funcionários em relação a 2012.
} 


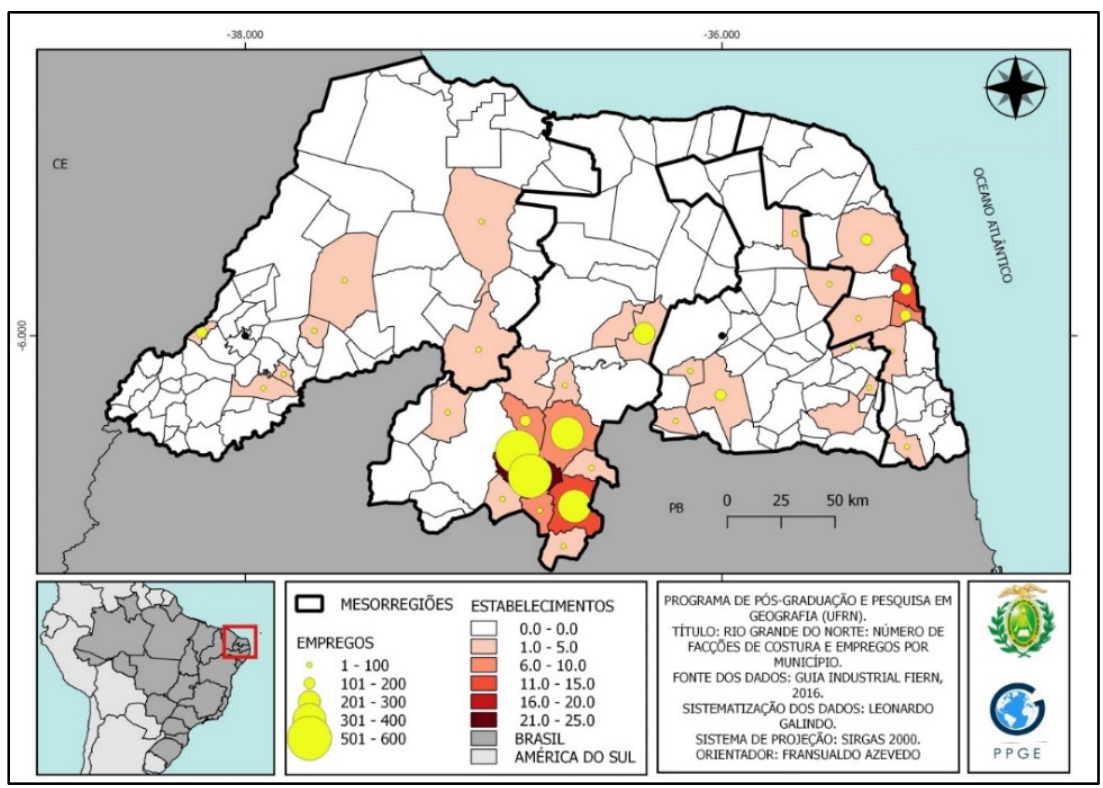

Figura 06: Rio Grande do Norte: Número de Estabelecimentos e Empregos Formais em Facções de Costura em 2016.

Fonte: GALINDO, 2018.

Nesse sentido, Natal e Parnamirim eram os lugares da fabricação do vestuário no RN. Com a nova divisão territorial do trabalho das empresas do setor, estas cidades reforçam seu comando na produção de roupas no RN. As grandes indústrias continuam realizando algumas etapas da fabricação, como o corte de tecidos; distribuição e supervisão das peças costuradas pelas facções, fazendo o controle de qualidade, e por fim a distribuição do vestuário para as redes varejistas em todo o Brasil.

Natal ainda apresenta-se como centro de comercialização de máquinas de costura atendendo empresas terceirizadas de todo o estado. Todavia, tanto Natal quanto Parnamirim vêm perdendo funcionários ligados à produção devido à redução da mão de obra nas grandes indústrias e ao fechamento de facções que atuavam em seus territórios. Na pesquisa de campo encontramos apenas três empresas funcionando em Natal, tendo o município de Parnamirim perdido todas as suas unidades produtivas (GALINDO, 2018). As facções ativas na capital apresentavam menos dinamismo que as do interior, com inferiores quantidades de funcionários e peças produzidas.

O preço da terra urbana é maior em Natal e Parnamirim do que no interior do estado. De fato, enquanto no Seridó os galpões de costura eram alugados ou cedidos, todas as três facções ativas em Natal funcionavam nas residências dos próprios empresários (figura 07). Nesse contexto, encontramos um empresário que transferiu sua unidade produtiva de Natal para Vera Cruz com o objetivo de economizar com o aluguel do galpão, encargos com transporte e alimentação. 


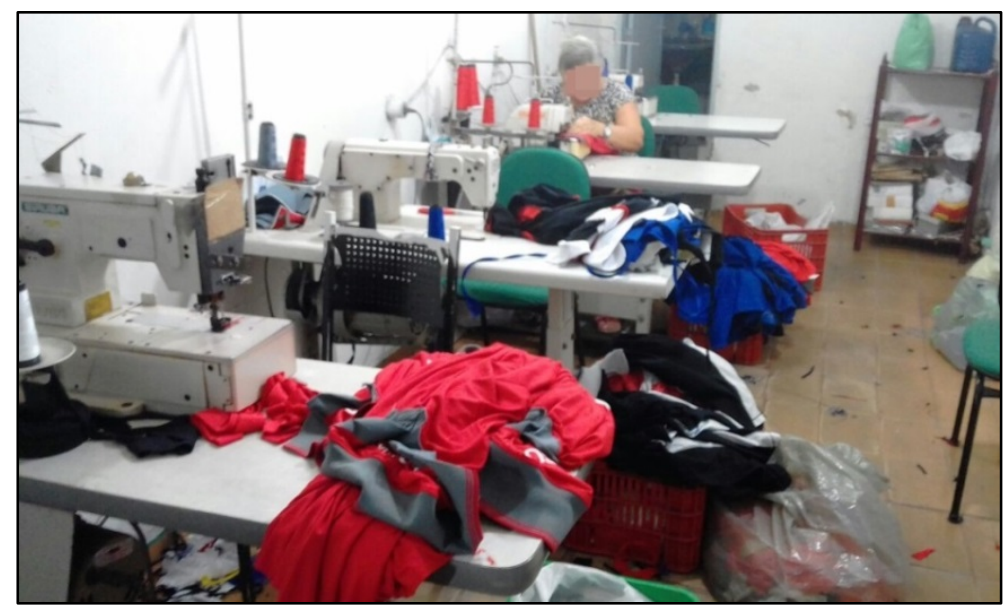

Figura 07: Facção de costura em Natal.

Fonte: GALINDO, 2018.

Mas por que as facções não prosperaram em lugares mais próximos a Natal e entorno? Uma primeira consideração é que a oferta de emprego formal na capital, maior em comparação com o interior, também está acessível para a maior parte dos moradores do agreste. Estes podem deslocar-se diariamente por meio de transporte público e ocupar vagas formais nos setores de comércio e serviços.

Os residentes nas demais mesorregiões (Central e Oeste) não têm a mesma facilidade do deslocamento diário (migração pendular) para trabalho em Natal justamente pela maior distância em relação a capital. Chegamos então ao papel desempenhado pelos municípios seridoenses (parte sul da mesorregião central).

\section{Especialização produtiva nos ramos têxteis e de confecções: A nova divisão interna do trabalho no Seridó Potiguar}

No processo de formação socioespacial brasileiro, cada lugar assumiu determinadas funções econômicas. O semiárido nordestino, do qual faz parte o Seridó potiguar destacouse pela cotonicultura e por atividades industriais ligadas a ela (AZEVEDO, 2013). Apesar do declínio dessa atividade, o saber fazer ligado a mesma acabou por estimular o surgimento de empresas ligadas ao setor têxtil e de confecções.

Com a reestruturação produtiva a partir dos anos 1970 houve várias transformações econômicas e socioterritoriais no RN (AZEVEDO, 2013). Nesse contexto, algumas cidades seridoenses (Caicó, Serra Negra do Norte, por exemplo) especializaram-se na confecção de 
acessórios do vestuário - bonés (LINS, 2011) e artefatos têxteis para uso doméstico ${ }^{10}$ (Caicó, Jardim de Piranhas) (AZEVEDO, 2017).

Nos anos 2000, em especial após 2010, os serviços terceirizados de costura surgiram naqueles municípios que se destacaram no passado pela produção de cotonicultura, e que não conseguiram se especializar na produção de bonés ou artefatos de uso doméstico. São lugares que apresentam grande exército de reserva de mão de obra, e, portanto, maior possibilidade de exploração do trabalho pela atividade terceirizada da costura.

Os serviços terceirizados de costura contribuíram para criar no Seridó uma divisão interna do trabalho voltada ao setor têxtil e de confecções (figura 08), em que cada município tem expressiva parcela de sua população empregada na produção de boné, costura de roupas, ou artefatos de uso doméstico.

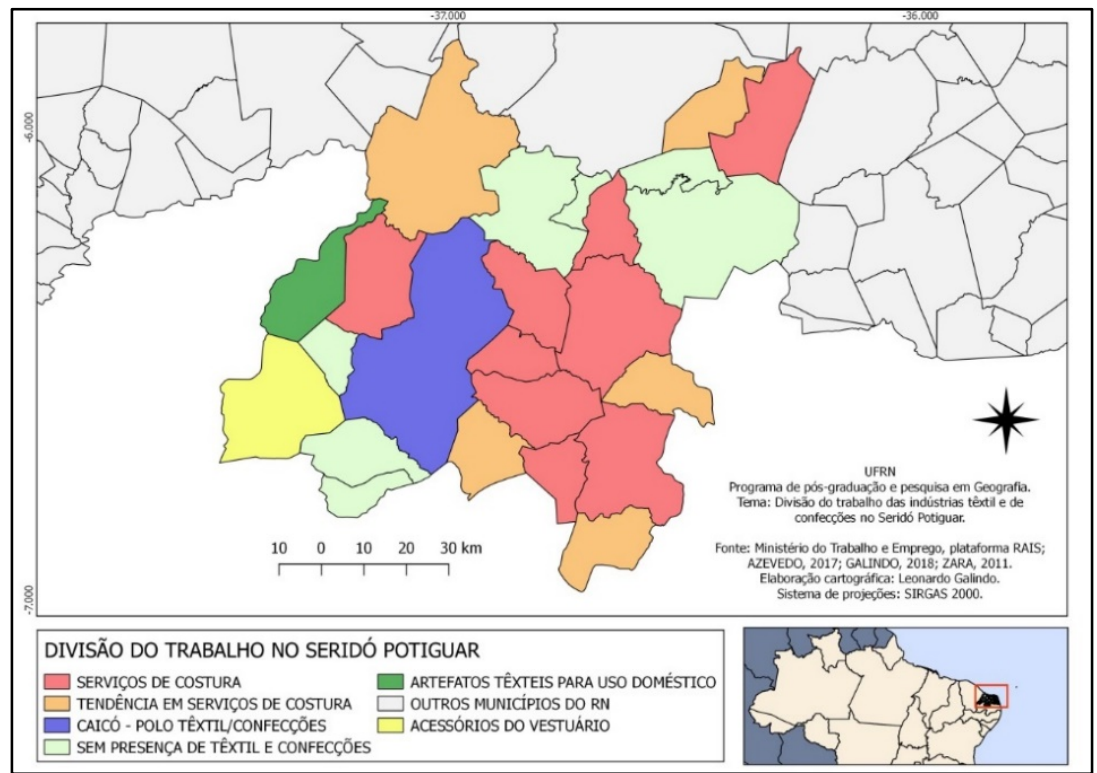

Figura 08: Divisão do trabalho das indústrias têxteis e de confecções no Seridó Potiguar.

Fonte: RAIS, 2016; AZEVEDO, 2017; GALINDO, 2018; ZARA, 2011. Elaboração cartográfica do autor.

Caicó apresenta-se como município polo por ter relações com os três ramos da produção têxtil e de confecções. É o que apresenta maior quantidade de mão de obra empregada na fabricação de bonés (RAIS, 2016), tem significativo número de trabalhadores na produção de artefatos para uso doméstico e apesar de não registrar serviços de costura para as grandes indústrias, fornece máquinas para pelo menos 26 facções de 7 municípios

\footnotetext{
${ }^{10}$ Envolve a produção de redes, toalhas de banho, cobertores, toalhas de prato, etc. Para mais informações consultar AZEVEDO, 2017.
} 
vizinhos. Antes, o comércio de máquinas atendia apenas o setor boneleiro (GALINDO, 2018).

Em função do porte dos municípios (tamanho da população), cada um especializouse em apenas um ramo. Jardim de Piranhas e Serra Negra do Norte dedicam-se respectivamente na produção de artefatos têxteis para uso doméstico e em acessórios do vestuário.

Em 8 municípios, há especialização produtiva com prestação de serviços de costura para as grandes fábricas. São José do Seridó tem mais de $55 \%$ da população com emprego formal dedicando-se a essa atividade. O número também é expressivo em Jardim do Seridó (32,7\%); Santana do Seridó (31,47\%); Cerro Corá (30,4\%); São Vicente (24,2\%); Acari $(20,97 \%)$; Cruzeta (18,3\%) e São Fernando (17,33\%) (RAIS, 2016).

Já 5 municípios seridoenses apresentam tendência em especializar-se na prestação de serviços de costura: Bodó, Jucurutu, Equador, Carnaúba dos Dantas, Ouro Branco. São lugares em que já atuam facções, mas a quantidade de mão de obra empregada não é expressiva proporcionalmente ao total de sua população quanto à do grupo anterior.

Outro grupo de municípios: Florânia, Lagoa Nova, Ipueira, Currais Novos, Timbaúba dos Batistas e Tenente Laurentino Cruz não apresenta especialização produtiva em nenhum dos três ramos apresentados. Não significa a inexistência dessas atividades em seus territórios. Indicam que os ramos têxtil e confecções são residuais considerando a quantidade de empregos formais.

Em relação aos trabalhadores, entrevistamos 32 funcionários, dos quais 5 trabalharam com carteira assinada antes do emprego atual. As experiências profissionais anteriores em empregos informais envolviam: babá, empregada doméstica, agricultor, com rendimento mensal que não ultrapassava meio salário mínimo.

Nesse contexto, a atividade de facções de costura encontrou no Seridó grande exército de reserva de mão de obra, já que para conseguir emprego formal, a maioria da população teria que migrar.

Considerando a figura 08, uma possível expansão das facções tem maior possibilidade de crescimento nos lugares agrupados como "tendência em serviços de costura". Em São Vicente, por exemplo, hoje com grande presença das facções, a atividade só começou a crescer depois de sua saturação em São José do Seridó, quando um família que controla 8 facções resolveu expandir suas atividades criando mais 3 empresas que terceirizam a costura. Como a atividade cresce em lugares com exército de reserva de mão de obra, os municípios classificados como "sem presença de têxtil e confecções" podem beneficiar-se de uma eventual expansão do setor em caso de esgotamento da mão de obra das cidades vizinhas.

Essa nova divisão do trabalho divisão evidencia o uso do território enquanto recurso (SANTOS, SILVEIRA, 2004) pelas empresas que comandam a produção do vestuário no RN. O exército de reserva de mão de obra e o saber fazer relacionado à produção têxtil com 
a existência prévia de empresas que comercializam máquinas de costura em Caicó são recursos que as grandes indústrias necessitam para ampliar seus lucros.

\section{Considerações finais}

O uso corporativo do território pela indústria do vestuário reconfigurou a divisão territorial do trabalho no RN. As mudanças no processo de produção, com ênfase na terceirização da costura e a solidariedade organizacional de agentes diversos, criou condições para municípios seridoenses especializarem-se na prestação de serviços para grandes indústrias que continuam dominando o processo produtivo no Rio Grande do Norte, sobretudo em Natal e Parnamirim.

O crescimento das facções reforça o papel da região enquanto produtora de bens dos ramos têxteis e vestuário criando uma divisão interna do trabalho, com municípios especializando-se na confecção de acessórios do vestuário, outros em artefatos têxteis para uso doméstico e outros nos serviços de costura. Neste último caso, o desenvolvimento da atividade beneficia os municípios, com aumento da oferta de emprego formal, da arrecadação de impostos e rebatimentos nos circuitos superior e inferior da economia regional.

O uso do território a partir da expansão das facções de costura é apresentado pelos agentes envolvidos em sua reprodução como panaceia para resolver todos os problemas regionais, especialmente no tocante a oportunidades de emprego e desenvolvimento econômico, posicionamento que precisa ser ponderado e visto com cautela, dadas as condições expostas e, sobretudo pela forte dependência perante grandes grupos econômicos.

Ressaltamos que tal atividade se alimenta justamente da presença de um exército de reserva de mão de obra que não tem outras opções de emprego formal. O uso corporativo do território por esse circuito produtivo existe porque os lugares são pobres e tem pessoas dispostas a trabalhar por baixos salários. E, o Seridó potiguar já desenvolvia outras atividades ligadas ao setor têxtil e confecções, contando com um saber fazer local que facilita o desenvolvimento das facções.

Assim, a atividade das facções de costura está completamente subordinada às grandes empresas. Estas, que enxergam o território enquanto recurso podem reconfigurar novamente seu processo produtivo, criando novas divisões do trabalho ao encontrarem lugares que lhe sejam mais rentáveis.

Nesse contexto, o uso do território é corporativo, mas não é a única possibilidade para os lugares. Há outras opções que podem diminuir a dependência para com as grandes empresas que controlam o processo, como associativismo, cooperativas, dentre outros. Pode-se, pelo menos no curto prazo, fortalecer solidariedade orgânica envolvendo os agentes seridoenses que poderiam articular-se com o objetivo de dominar mais etapas do processo de produção do vestuário e ampliar seu número de clientes. 


\section{Referências}

ANDRADE, Manuel Correia de. A produção do espaço norte-rio-grandense. Editora universitária UFRN. Natal, 1995.

ARAÚJO, Denílson da Silva. Dinâmica econômica, urbanização e metropolização no Rio Grande do Norte (1940-2006). Tese (doutorado) - Universidade Estadual de Campinas, Instituto de Economia. - Campinas, SP: [s.n.], 2009.

ARROYO, Monica; GOMES, Rita de Cássia da Conceição. O Rio Grande Do Norte No Comércio Internacional: circuito espacial da produção de têxteis e de confecções. Mercator, Fortaleza, v. 12, n. 29, p. 31-38, set./dez. 2013.

AZEVEDO, Francisco Fransualdo de. Reestruturação Produtiva no Rio Grande do Norte. Mercator, Fortaleza, v. 12, número especial (2)., p. 113-132, set. 2013.

AZEVEDO, Francisco Fransualdo de; GALINDO, Leonardo da Silva. A espacialidade da indústria no Rio Grande do Norte (Brasil) no contexto da reestruturação produtiva. Boletim Gaúcho de Geografia, v.42, n. 2: 147-168, 2016. Porto Alegre - RS.

AZEVEDO, Igor Rasec Batista de. Circuito espacial da produção têxtil no Seridó Potiguar: as especificidades do ramo de artefatos domésticos. 2017. 243f. Dissertação (Mestrado em Geografia) - Centro de Ciências Humanas, Letras e Artes, Universidade Federal do Rio Grande do Norte, Natal, 2017.

BARBOSA, Jane Roberta de Assis. Planejamento Territorial e Modernizações Seletivas: a expansão do meio técnico-cientifico-informacional no Rio Grande do Norte, Brasil. Tese (Doutorado) - Faculdade de Filosofia, letras e Ciências Humanas da universidade de São Paulo. São Paulo, 2015.

CANO, Wilson. Desequilíbrios regionais e concentração industrial no Brasil, 1930 - 1995. 2. ed. Ver. aum. - Campinas, SP: UNICAMP . IE, 1998.

CANO, Wilson. Raízes da Concentração industrial em São Paulo. 4. Ed. Campinas - SP: UNICAMP, 1998a).

DANTAS, Aldo. Circuito espacial de produção e lugar. Sociedade e Território - Natal. Vol. 28, N. 1, p. 193 -199. Jan./Jun. de 2016

FEDERAÇÃO DAS INDÚSTRIAS DO ESTADO DO RIO GRANDE DO NORTE- FIERN. Guia Industrial Sistema FIERN. Disponível em: < http://guiaindustrial.fiern.org.br/consulta.php $>$ acesso em 15 dez. 2016.

FURTADO, Celso. Formação Econômica do Brasil. 34. Ed. Editora Nacional, São Paulo, 2007.

IBGE. Classificação nacional de atividades econômicas: versão 2.0. Disponível em: < https://biblioteca.ibge.gov.br/visualizacao/livros/liv36932.pdf >. Acesso em 18 out. 2018.

IBGE. Cidades. Disponível em: < https://cidades.ibge.gov.br/>. Acesso em 25 jul. 2018. 
IBGE. Pesquisa Industrial Anual. Disponível em: < https:/www.ibge.gov.br/estatisticasnovoportal/economicas/industria/9042-pesquisa-industrial-anual.html? \&t=series-historicas $>$ Acesso em 02 nov. 2017.

IBGE - INSTITUTO BRASILEIRO DE GEOGRAFIA E ESTATÍSTICA. Censo Industrial Rio Grande do Norte 1970. Disponível em: <

https://biblioteca.ibge.gov.br/visualizacao/periodicos/101/ci_1970_v4_t8_rn.pdf $>$ Acesso em 12. Jan. 2017.

GALINDO, Leonardo da Silva. Uso corporativo do território e "facções" de costura: a reorganização espacial do setor de confecções de artigos do vestuário no Rio Grande do Norte. 2018. 243f. Dissertação (Mestrado em Geografia) - Centro de Ciências Humanas, Letras e Artes, Universidade Federal do Rio Grande do Norte, Natal, 2018.

KAHIL, Samira Peduti. Psicoesfera: uso corporativo da esfera técnica do território e o novo espírito do capitalismo. Sociedade \& Natureza, Uberlândia, 22 (3): 475-485, dez. 2010.

LINS, Zara de Medeiros. Circuitos espaciais de produção da atividade boneleira: o uso dos territórios de Caicó, Serra Negra do Norte e São José do Seridó. 2011. 242 f. Dissertação (Mestrado em Dinâmica e Reestruturação do Território) - Universidade Federal do Rio Grande do Norte, Natal, 2011.

LUCLKTENBERG, Isabela Albertina Barreiros. A Indústria Têxtil Catarinense e o caso da Cia Hering. Mestrado em Geografia. Universidade Estadual Paulista Júlio de Mesquita Filho, UNESP. Presidente Prudente, 2004. $261 \mathrm{fl}$.

MORAIS, Ione Rodrigues Diniz. Seridó norte-rio-grandense: uma geografia da resistência. Caicó. Editora: Edição do autor. 2005.

MINISTÉRIO DO TRABALHO E EMPREGO. Plataforma RAIS (Relação Anual de Informações Sociais). Disponível em:

$<$ http://bi.mte.gov.br/bgcaged/caged_rais_vinculo_id/caged_rais_vinculo_basico_tab.php $>$. Acesso em 01 jul. 2019.

PEREIRA JÚNIOR, Edilson Alves. Território e economia política: uma abordagem a partir do novo processo de industrialização no Ceará. Tese (doutorado) - Universidade Estadual Paulista, Faculdade de Ciências e Tecnologia - Presidente Prudente: [s.n], 2011. 450 f.

REOLON, Cleverson Alexsader. Produção Industrial e Comando do Capital no Brasil: Uma Análise Espacial. 1. Ed. - São Paulo: Cultura Acadêmica, 2013.

SANTOS, Milton; SILVEIRA, Maria Laura. O Brasil: território e sociedade no início do século XXI. 6 ed. Rio de Janeiro. Record: 2004.

SANTOS, Milton. Por Uma Geografia Cidadã: Por Uma Epistemologia Da Existência. Boletim Gaúcho de Geografia, 21: 7-14, ago., 1996. Disponível em:

$<$ http://seer.ufrgs.br/bgg/article/view/38613/26350>. Acesso em 19 dez. 2016.

SANTOS, Milton. O retorno do território. En: OSAL: Observatorio Social de América Latina. Año 6 no. 16 (jun.2005- ). Buenos Aires : CLACSO, 2005. 
SANTOS, Milton. A natureza do Espaço: técnica e tempo. Razão e emoção. 4. Ed. $7^{\circ}$ Reimpr. São Paulo: editora da Universidade de São Paulo, 2012.

SEBRAE. Ideias de negócios: Como montar um serviço de confecção. Disponível em: http://www.sebrae.com.br/sites/PortalSebrae/ideias/como-montar-um-servico-deconfeccao,89387a51b9105410VgnVCM1000003b74010aRCRD> Acesso em 10 fev. 2017.

SEBRAE. Pró-Sertão - Programa de industrialização do interior: Perfil facção de costura: tecido plano. 2013. Disponível em:

$<$ http://www.sebrae.com.br/Sebrae/Portal\%20Sebrae/UFs/RN/Anexos/perfis-pro-sertao-tecidopano.pdf> . Acesso em 12 mar. 2017.

SILVA, Silvana C. da. A reorganização do circuito espacial da produção do vestuário no Brasill. Espaço e Economia, p. 1-10, 2013.

TAVARES, Matheus Augusto Avelino. O Uso do Território pelos circuitos espaciais de produção da indústria no Rio Grande do Norte. Tese (doutorado) - Faculdade de Filosofia, Letras e Ciências Humanas da Universidade de São Paulo. Departamento de Geografia. São Paulo, 2017.

* Parte da discussão apresentada neste texto resulta da dissertação "uso corporativo do território e facções de costura: a reorganização espacial do setor de confecções de artigos do vestuário do Rio Grande do Norte”, defendida em 2018.

Leonardo da Silva Galindo

Mestre e licenciado em Geografia pela Universidade Federal do Rio Grande do Norte. Atualmente é professor de geografia pela rede pública de ensino do estado do Rio Grande do Norte.

UFRN, Campus Universitário Lagoa Nova - CCHLA - Av. Salgado Filho. Lagoa Nova. Cep: 59072-970 - Natal, RN - Brasil - Caixa-postal: 1524.

E-mail: leonardogalindo.ufrn@gmail.com

Francisco Fransualdo de Azevedo

Doutor em Geografia pela Universidade Federal de Uberlândia. Atualmente é Professor do Departamento de Geografia da Universidade Federal do Rio Grande do Norte e Docente Permanente dos Programas de Pós-Graduação em Geografia e Turismo. UFRN, Campus Universitário Lagoa Nova - CCHLA - Av. Salgado Filho. Lagoa Nova. Cep: 59072-970 - Natal, RN - Brasil - Caixa-postal: 1524.

E-mail: ffazevedo@gmail.com.

Recebido para publicação em julho de 2019

Aprovado para publicação em setembro 2019 